\title{
BMJ Open Quality Point-of-care C-reactive protein testing to optimise antibiotic use in a primary care urgent care centre setting
}

To cite: Ward C. Point-of-care C-reactive protein testing to optimise antibiotic use in a primary care urgent care centre setting. BMJ Open Quality 2018;7:e000391. doi:10.1136/ bmjoq-2018-000391

Received 12 April 2018 Revised 26 July 2018 Accepted 21 August 2018
Check for updates

(c) Author(s) (or their employer(s)) 2018. Re-use permitted under CC BY-NC. No commercial re-use. See rights and permissions. Published by BMJ.

${ }^{1}$ Swindon Clinical Commissioning Group, The Pierre Simonet Building, North Latham Road, Swindon, UK ${ }^{2}$ West of England Academic Health Science Network, South Plaza, Marlborough Street, Bristol, UK

Correspondence to Dr Caroline Ward; caroline.ward@doctors.org.uk

\section{PROBLEM}

The rate of antimicrobial prescribing in UK general practice is falling year on year and data from the Swindon Clinical Commissioning Group (CCG) area are no exception. ${ }^{1}$ However, looking at the local data more closely, there appeared to be an increasing trend in antimicrobial prescribing in the local urgent care centre, which included broad spectrum increase, which was at odds with local usage within 'in-hours' general practice.

\section{BACKGROUND}

Most UK general practices prescribe antibiotics for respiratory tract infections at rates that are not clinically justified. Around 48\% of patients presenting to a general practitioner (GP) with symptoms of cough or bronchitis will receive an antibiotic, although the majority of these infections are of viral origin and therefore antibiotics are not required. ${ }^{2}$

Identifying strategies to help clinicians reduce unnecessary antibiotic prescribing in common infections is a key aim within the Department of Health's 'UK Five Year Antimicrobial Resistance Strategy'.

Backup (or delayed) prescribing can reduce antibiotic consumption. Studies have shown that fewer than $40 \%$ of patients given a backup antibiotic will use it. ${ }^{4}$

Point-of-care testing (POCT) of C-reactive protein (CRP) in primary care is not widespread in the UK but is more common in other European countries. The National Institute for Health and Care Excellence (NICE) recommends point-of-care (POC) CRP testing in primary care to aid diagnosis in guideline CG191 'Pneumonia in adults: diagnosis and management'. ${ }^{2}$ Based on the recommendations in this guidance, a rapid POCT machine was installed within the centre for use by all clinicians. A 6-month pilot study aimed to assess whether CRP testing reduced the frequency of unnecessary antibiotic prescriptions in viral or self-limiting lower respiratory tract infections, and to determine the cost impact and sustainability of testing.

\section{DESIGN AND METHODS}

Swindon Urgent Care Centre (UCC) provides primary care services to a population of around 230000. It is staffed by GPs, nurse practitioners and other emergency care practitioners. It provides primary care services outwith standard general practice opening times, and also sees some acute patients referred by the local Accident and Emergency or as 'walk-in' patients. In August 2016, a 6-month pilot study was commenced to determine whether POCT would reduce unnecessary antibiotic prescriptions in viral lower respiratory tract infections, and to assess the cost impact and sustainability of POCT.

An Alere Afinion machine was placed in the UCC for the duration of the 6-month study. This offers finger-prick CRP testing with results available within $4 \mathrm{~min}$. Criteria for CRP testing and subsequent patient management were as per the following recommendations from NICE guidance 'Pneumonia in adults: diagnosis and management ${ }^{5}$ :

Results of C-reactive protein testing to guide antibiotic prescribing in people without a clinical diagnosis of pneumonia were implemented as follows:

- Do not routinely offer antibiotic therapy if CRP is less than $20 \mathrm{mg} /$ litre.

- Consider a back-up antibiotic prescription if the CRP is $20-100 \mathrm{mg} /$ litre.

- Offer antibiotic therapy if the CRP is greater than $100 \mathrm{mg} /$ litre.

In order to ensure that the machine was being used consistently and appropriately, we developed a protocol, flow chart and simple audit sheet to be followed and completed by clinicians.

With each CRP testing cartridge costing approximately $£ 4$, and tests adding several minutes to each consultation, we tried to 


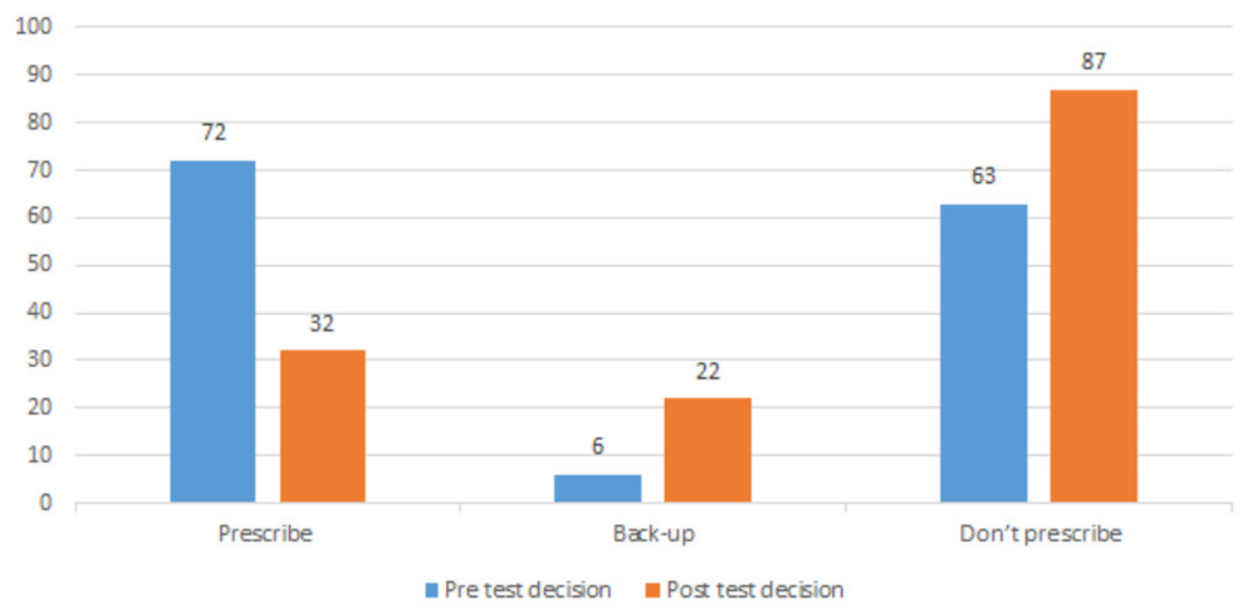

Figure 1 Comparison of pretest and post-test prescribing decisions.

ensure that clinicians only tested when, after history and examination, diagnostic uncertainty remained about whether symptoms represented viral respiratory tract infection or bacterial pneumonia.

We anticipated and budgeted for the use of around 10 CRP tests each day. Swindon CCG agreed to provide funding for CRP test cartridges in the UCC. The machine was provided for free by the manufacturer for the duration of the pilot.

\section{RESULTS}

A total of 208 test cartridges were used, however, we analysed data from only 141 tests as we excluded any data sets which were incomplete and those consumed in quality control.

Based on pretest decision (ie, the decision that would have been made if no test was available), results showed that 72 of the 141 patients $(51.1 \%)$ would have been given an immediate antibiotic prescription, $6(4.2 \%)$ would have been given a backup prescription and $63(44.1 \%)$ would not have received an antibiotic. After CRP testing, $32(22.7 \%)$ patients received an immediate antibiotic, 22 $(15.6 \%)$ received a backup prescription and 87 (61.7\%) received no antibiotic (figure 1 ).

Although the overwhelming trend was from 'prescribe' to either 'back-up' or 'don't prescribe', there were nine patients where the decision changed from no antibiotics to immediate antibiotics after testing. CRP results in this group ranged from 28 to $155 \mathrm{mg} / \mathrm{L}$, with the majority being less than $100 \mathrm{mg} / \mathrm{L}$.

Antibiotics were sometimes prescribed despite a CRP of $<5$. The reasons documented for this were duration of symptoms (typically longer than 3 weeks), sputum colour (yellow, green or brown) or existing comorbidity.

The costs of this project were much lower than anticipated. A total of 208 cartridges were used at a cost of approximately $£ 4$ each, making a total spend of $£ 832$ over 6 months. We were initially surprised by this, although on reflection, we felt that cases of true diagnostic uncertainty after history and clinical examination are the exception.

\section{CONCLUSION AND DISCUSSION}

This study demonstrated that POC CRP testing in a defined clinical population is a useful tool to optimise antimicrobial prescribing in primary care. A clear shift was seen towards either no prescribing or backup prescribing after testing. While most prescribing decisions seemed appropriate, the results showed that additional training in judicious antibiotic use could further reduce inappropriate prescribing.

Testing was strictly controlled in this study to a well-defined population and in a single disease condition. Further consideration may need to be given to the issue of cost-effectiveness if testing is expanded in other infective conditions.

POC CRP testing has the potential to facilitate antimicrobial stewardship in primary care. However, care must be taken to ensure it is used in a cost-effective and evidence-based manner. Further research and guidance is needed to determine the usefulness of POC CRP testing in the wider primary care community and in other common disease areas.

Acknowledgements We thank all staff at the Urgent Care Centre in Swindon for their cooperation and assistance with this project, particularly Dr Christopher Turner and Andrew Woodruffe. Thank you to Swindon CCG for providing funding and support for the project. Thank you to the West of England AHSN and CLARHC West/University of the West of England, particularly Dr Issy Bray, Abby Sabey, Jo Bangoura and Dr Peter Brindle for your tireless enthusiasm and support of the GP Clinical Evidence Fellow Programme.

Collaborators Julian Hick.

Contributors CW conceived the idea, did literature search, designed the pilot study, collected data, and wrote and proofread the manuscript. Julian Hick was involved in data management and analysis.

Funding Swindon Clinical Commissioning Group provided funding for test cartridges.

Competing interests None declared.

Patient consent Not required.

Provenance and peer review Not commissioned; internally peer reviewed.

Data sharing statement There are no unpublished data from the study.

Open access This is an open access article distributed in accordance with the Creative Commons Attribution Non Commercial (CC BY-NC 4.0) license, which permits others to distribute, remix, adapt, build upon this work non-commercially, and license their derivative works on different terms, provided the original work is 
properly cited, appropriate credit is given, any changes made indicated, and the use is non-commercial. See: http://creativecommons.org/licenses/by-nc/4.0/.

\section{REFERENCES}

1. Public Health England. English surveillance programme for antimicrobial utilisation and resistance (ESPAUR. London: PHE, 2017.

2. Gulliford MC, Dregan A, Moore MV, et al. Continued high rates of antibiotic prescribing to adults with respiratory tract infection: survey of 568 UK general practices. BMJ Open 2014;4:e006245.
3. Department of Health and Department for Environment, Food and Rural Affairs. UK 5 Year antimicrobial resistance strategy 2013 to 2018. https://www.gov.uk/government/uploads/system/uploads/ attachment_data/file/244058/20130902_UK_5_year_AMR_strategy. pdf.

4. Little P, Moore M, Kelly J, et al. Delayed antibiotic prescribing strategies for respiratory tract infections in primary care: pragmatic, factorial, randomised controlled trial. BMJ 2014;348:g1606.

5. NICE. Pneumonia- Diagnosis and management of community- and hospital-acquired pneumonia in adults, 2014. 